\title{
Extração de pectina de goiaba desidratada
}

\author{
Extraction of pectin from dehydrated guava
}

\section{Cláudia Leite MUNHOZ ${ }^{1 *}$, Eliana Janet SANJINEZ-ARGANDOÑN², Manoel Soares SOARES-JÚNIOR ${ }^{3}$}

\section{Resumo}

Goiabas (Psidium guajava L.) cultivar Pedro Sato foram utilizadas para extração de pectina. Os frutos separados polpa e polpa com casca foram secos em estufa com circulação de ar. Amostras secas foram caracterizadas física e quimicamente. O planejamento composto central rotacional com quatro pontos axiais e três repetições no ponto central foi utilizado para determinar o rendimento de extração de pectina das farinhas de polpa e de polpa com casca de goiaba. A extração foi realizada em $4 \mathrm{~g}$ de farinha para $200 \mathrm{~mL}$ de solução de ácido cítrico em diferentes concentrações e em diferentes tempos de extração, a temperatura de $97^{\circ} \mathrm{C}$. As pectinas obtidas nas melhores condições de extração foram caracterizadas. A extração de pectina com ácido cítrico e precipitação alcoólica forneceu rendimentos acima de $11 \%$ para a farinha de polpa e de polpa com casca de goiaba. As melhores condições de extração foram: concentração de ácido cítrico de 5 g. 100 g ${ }^{-1}$ e tempo de extração de 60 minutos. As pectinas obtidas apresentaram-se de baixa esterificação e com teor de ácido galacturônico próximo ao padrão comercial (65\%).

Palavras-chave: pectina; extração ácida; Psidium guajava L.

\begin{abstract}
Pedro Sato cultivar guavas (Psidium guajava L.) were used for extraction of pectin. The fruits were divided into pulp and pulp with peel, and dried in a stove with air circulation. Dry samples were characterized physically and chemically. The planning consisted of central axial rotation with four points, and three replicates in the central point were used to determine the extraction yield of pectin flour from the guava pulp and pulp with peel. The extraction was performed in $4 \mathrm{~g}$ of flour to $200 \mathrm{~mL}$ of solution of citric acid at different concentrations and at different times of extraction, at a temperature of $97^{\circ} \mathrm{C}$. The pectins obtained in optimum conditions for extraction were characterized. The extraction of pectin with citric acid and alcohol precipitation provided yield above $11 \%$ for the guava flour, with pulp and pulp with peel. The best conditions for the extraction were: concentration of citric acid $5 \mathrm{~g} .100 \mathrm{~g}^{-1}$ and extraction time of 60 minutes. Pectins obtained demonstrated low esterification and with a level of galacturonic acid close to the commercial standard (65\%).

Keywords: pectin; acid extraction; Psidium guajava L.
\end{abstract}

\section{Introdução}

A pectina é um polissacarídeo constituinte da parede celular de plantas dicotiledôneas, responsável pela adesão entre as células e pela resistência mecânica da parede celular. A associação de pectina entre celulose e hemicelulose origina a protopectina nos tecidos vegetais. A protopectina, de natureza insolúvel, é facilmente hidrolisada por aquecimento, em meio ácido, formando pectina (ORDOÑEZ-PEREDA; 2005; THAKUR; SINGH; HANDA, 1997).

A importância da pectina em alimentos é geralmente atribuída à formação de géis, sendo amplamente usada na produção de gomas, geleias, produtos lácteos, entre outros (THAKUR; SINGH; HANDA, 1997; WILLATS; KNOX; MIKKELSEN, 2006). No entanto, nos últimos anos, a pectina vem sendo empregada também como fibra dietética solúvel por apresentar efeitos fisiológicos benéficos ao organismo humano, tais como redução dos níveis de colesterol, lipoproteínas, ácidos biliares e glicose (FIETZ; SALGADO, 1999; PIEDADE; CANNIATTI-BRAZACA, 2003; TERPSTRA et al., 1998).

As substâncias pécticas são geralmente extraídas por métodos químicos e enzimáticos. A extração de pectina é um processo de múltiplos estágios físicos e químicos nos quais a hidrólise, a extração e a solubilização de macromoléculas do tecido vegetal são influenciadas por diversos fatores como temperatura, $\mathrm{pH}$, tipo de ácido e tempo de extração (PAGAN et al., 2001). A pectina pode ser produzida a partir da mistura do extrato líquido com álcool, sendo precipitada, seca e triturada (MAY, 1990).

Embora as fontes mais usuais para a extração de pectina comercial sejam os albedos cítricos e o bagaço de maçã (MAY, 1990; THAKUR; SINGH; HANDA, 1997), as pectinas extraídas apresentam características diferentes (grau de esterificação, tamanho das partículas, conteúdo de açúcares, teor de cinzas

Recebido para publicação em 24/2/2008

Aceito para publicação em 24/7/2008 (003256)

${ }^{1}$ Ciência e Tecnologia de Alimentos, Universidade Federal de Goiás - UFG, Rua Bernardo Baur, 1142, CEP 79710-000, Vicentina - MS, Brasil, E-mail: clmunhoz@yahoo.com.br

${ }^{2}$ Universidade Federal da Grande Dourados - UFGD, Dourados - MS, Brasil

3 Universidade Federal de Goiás - UFG, Goiânia - GO, Brasil

${ }^{*}$ A quem a correspondência deve ser enviada 
e outros) e têm consequentemente propriedades funcionais diferentes, o que possibilita o estudo de fontes alternativas de extração. Atualmente, existem inúmeras pesquisas sobre extração de pectina de diferentes fontes, ressaltando-se o aproveitamento de resíduos de indústrias (GNANASAMBANDAM; PROCTOR, 1999; WILLATS; KNOX; MIKKELSEN, 2006).

A goiaba é rica em pectina, sendo seu teor influenciado por fatores como cultivar, estádio de maturação, época de desenvolvimento dos frutos e fatores climáticos (CERQUEIRA, 2007). Há vários estudos de aproveitamento de diferentes resíduos para extração de pectina, no entanto, apesar da goiaba (Psidium guajava L.) conter pectina, existem poucas informações sobre o seu uso como fonte de extração. Diante do exposto, o objetivo deste trabalho foi extrair pectina das farinhas de polpa e da polpa com casca de goiaba e caracterizá-las quanto ao grau de esterificação.

\section{Material e métodos}

\subsection{Material}

A matéria-prima objeto de investigação deste trabalho foi a goiaba (Psidium guajava L.) vermelha da cultivar Pedro Sato. As goiabas foram adquiridas no distrito de Santa Terezinha, município de Itaporã-MS.

\subsection{Métodos}

\section{Preparo da matéria-prima}

Foram selecionados $20 \mathrm{~kg}$ de goiabas de acordo com o peso (130 a $140 \mathrm{~g}$ ), tamanho, aparência (frutas sadias), formato (uniforme) e grau de maturação maduro definido pela coloração amarela da casca, observada visualmente, a fim de se obter amostras mais homogêneas.

Os frutos foram lavados, sanitizados com dicloro s. triazinatriona sódica di-hidratada, da marca Sumaveg, na concentração de $0,66 \%$ por 10 minutos e levemente enxugadas com papel absorvente. Em seguida, os frutos foram divididos e fracionados para posterior secagem: 1) polpa com casca, sem miolo e 2) goiabas descascadas e sem miolo (polpa). As frações foram secas separadamente em estufa com circulação forçada de ar a $55^{\circ} \mathrm{C}$ durante 72 horas e moídas em moinho de facas da marca Marconi, até obtenção das farinhas e armazenadas em recipientes de vidro hermeticamente fechados.

\section{Caracterização física e química das}

farinhas das frações de goiaba

Amostras das farinhas obtidas foram submetidas às análises descritas a seguir. Os teores de umidade foram determinados por secagem das amostras em estufa a $105^{\circ} \mathrm{C}$ até peso constante, as cinzas foram quantificadas utilizando-se o método de incineração a $550^{\circ} \mathrm{C}$ e a acidez titulável por titulação com $\mathrm{NaOH}$ $0,1 \mathrm{~N}$, de acordo com as técnicas descritas pelo Instituto Adolfo Lutz (2005). Os teores de açúcares totais e de redutores foram determinados pelo método químico de Lane-Eynon baseado na oxidação do cobre (RANGANNA, 1977). As determinações das atividades de água foram realizadas por meio de medidas diretas em higrômetro Aqualab, modelo CX-2T (Aqualab Decagon Devices Inc., USA) à temperatura de $25^{\circ} \mathrm{C}$. Os pHs das amostras foram medidos por meio de leitura direta em potenciômetro digital, marca Mettler Toledo, modelo pH320, previamente calibrado com soluções-padrão de pHs 4 e 7 , a partir da solubilização das amostras com água destilada. A quantificação dos teores de pectina seguiu a metodologia descrita por Ranganna (1977). Todas as análises foram realizadas em triplicata.

\section{Planejamento experimental}

O rendimento de extração de pectina foi determinado seguindo um delineamento composto central rotacional com quatro pontos axiais e três repetições no ponto central, totalizando 11 ensaios (Tabela 1). Os fatores escolhidos para avaliar o rendimento de extração de pectina foram concentração de ácido (g.L $\left.\mathrm{L}^{-1}\right)$ e tempo de extração (minutos), denominados variáveis independentes. $\mathrm{O}$ rendimento em massa de pectina, extraída em cada experimento, foi considerado a variável resposta ou dependente. Os experimentos foram realizados em duplicata.

A pectina foi extraída em meio ácido, com ácido cítrico. O procedimento para extração de pectina da goiaba foi realizado com as farinhas da polpa e da polpa com casca. As amostras de farinha de goiaba $(4 \mathrm{~g})$ foram dissolvidas em $200 \mathrm{~mL}$ de água destilada. As extrações foram realizadas à temperatura constante $\left(97^{\circ} \mathrm{C}\right)$ sob diferentes condições de concentração de ácido (3,5 a 7,0\%) e de tempo (25 a 95 minutos). Após extração ácida, as amostras foram resfriadas a $4{ }^{\circ} \mathrm{C}$ por duas horas, filtradas em tecido de poliéster, sendo descartado o sobrenadante. Ao filtrado, contendo pectina, foi adicionado álcool etílico (95\%) na proporção 1:2 (uma parte de solução de pectina e duas partes de álcool). Após uma hora, houve a separação da pectina na forma de precipitado, sendo separada por filtração. A pectina obtida foi seca em estufa de secagem a $55^{\circ} \mathrm{C}$ até peso constante. $\mathrm{O}$ rendimento de pectina foi obtido a partir da quantidade inicial da matéria-prima utilizada (Equação 1).

Tabela 1. Variáveis codificadas e reais empregadas para a extração de pectina no delineamento experimental $2^{2}$.

\begin{tabular}{cccccc}
\hline Experimento & \multicolumn{2}{c}{ Variáveis codificadas } & & \multicolumn{2}{c}{ Variáveis reais } \\
\cline { 2 - 3 } \cline { 5 - 6 } & $\begin{array}{c}\text { Ácido } \\
(\%)\end{array}$ & $\begin{array}{c}\text { Tempo } \\
\text { (minutos) }\end{array}$ & & $\begin{array}{c}\text { Ácido } \\
(\%)\end{array}$ & $\begin{array}{c}\text { Tempo } \\
\text { (minutos) }\end{array}$ \\
\hline 1 & -1 & -1 & & 3,5 & 35 \\
2 & 1 & -1 & & 6,5 & 35 \\
3 & -1 & 1 & & 3,5 & 85 \\
4 & 1 & 1 & & 6,5 & 85 \\
5 & $-1,414$ & 0 & 3 & 60 \\
6 & 1,414 & 0 & & 7 & 60 \\
7 & 0 & $-1,414$ & 5 & 25 \\
8 & 0 & 1,414 & & 5 & 95 \\
9 & 0 & 0 & & 5 & 60 \\
10 & 0 & 0 & & 5 & 60 \\
11 & 0 & 0 & 5 & 60 \\
\hline
\end{tabular}


Rendimento $=\frac{\text { pectina }_{\text {extraída }} \times 100}{\text { massa }_{\text {farinha(seca) }}}$

em que:

Pectina $_{\text {extraída }}=$ massa de pectina obtida após extração e secagem em gramas; e

Massa $_{\text {farinha (seca) }}=$ massa da amostra em base seca em gramas .

\section{Caracterização titulométrica da pectina das farinhas de polpa e de polpa com casca de goiaba}

As amostras de pectina obtidas nas condições experimentais $5 \mathrm{~g} .100 \mathrm{~g}^{-1}$ e tempo de 60 minutos foram quantificadas por titulometria (WANG; PAGAN; SHI, 2002 apud FERTONANI, 2006). Aproximadamente $250 \mathrm{mg}$ de pectina foi umedecida com $2 \mathrm{~mL}$ de álcool etílico P.A. e solubilizada em $25 \mathrm{~mL}$ de água deionizada sob agitação constante por 30 minutos em agitador magnético, sendo em seguida determinado o $\mathrm{pH}$ da solução. As carboxilas livres dos ácidos anidrogalacturônicos foram neutralizadas com solução de $\mathrm{NaOH} 0,1 \mathrm{~N}$. As carboxilas esterificadas após saponificação com $10 \mathrm{~mL}$ de solução de $\mathrm{NaOH} 0,25 \mathrm{~N}$ por 30 minutos em temperatura ambiente foram neutralizadas com $10 \mathrm{~mL}$ de solução de $\mathrm{HCl} 0,25 \mathrm{~N}$ e novamente neutralizadas com solução de $\mathrm{NaOH} 0,1 \mathrm{~N}$, obtendo-se então os valores de $\mathrm{mEq}$ de $\mathrm{NaOH}$ referentes aos dois tipos de carboxilas, livres e esterificadas, respectivamente representados por $\mathrm{mEq}$ ' e $\mathrm{mEq}$ ". Com os dados obtidos foram realizados os cálculos para determinação da quantidade de massa por mEq (Equação 2), teor de resíduos galacturônicos (Equação 3), teor de metoxilas (Equação 4), percentual de ácidos poligalacturônicos (Equação 5), percentual de açúcares neutros (Equação 6) e grau de esterificação (Equação 7).

$$
\begin{aligned}
& \mathrm{Z}=\frac{\text { massa }_{\text {pectina }}}{\mathrm{mEq}_{\text {totais }}} \\
& \mathrm{AUA}(\%)=\frac{17600}{\mathrm{Z}} \\
& \mathrm{MeO}(\%)=\frac{\left(\mathrm{mEq} \text { massa }_{\text {pectina }}\right.}{\text { Fração }_{\text {ácida }}=\mathrm{AUA}(\%)+\mathrm{MeO}(\%)} \\
& \text { Fração } \\
& \text { neutra } \\
& \mathrm{DE}=\left(\frac{176}{31}\right) \times\left(\frac{\mathrm{MeO}}{\mathrm{AUA}}\right)
\end{aligned}
$$

em que:

$\mathrm{Z}$ = quantidade de massa por mili-equivalente-grama;

$\mathrm{mEq}=$ mili-equivalente-grama;

AUA = teor de resíduos de ácido anidrogalacturônico;

$\mathrm{MeO}=$ teor de metoxilas; e

DE = grau de esterificação.

\section{Análise estatística}

Os dados obtidos relativos à característica física e química da matéria-prima, de suas frações e de suas farinhas foram analisados pelo cálculo da média, desvio padrão, coeficiente de variação e análises de variância. Para a comparação das médias, foi empregado o teste Tukey ao nível de 5\% de probabilidade. Os dados de rendimento de pectina obtidos foram submetidos à análise de variância por meio do aplicativo SAS (SAS INSTITUTE, 1992).

\section{Resultados e discussão}

\subsection{Características físicas e químicas das frações das farinhas}

As características físicas e químicas das farinhas obtidas a partir da polpa e da polpa com casca de goiaba estão apresentadas na Tabela 2. Poucos trabalhos têm sido realizados a respeito de farinhas obtidas do fracionamento de frutos e nenhum trabalho de goiaba foi encontrado, o que propiciou o estudo das farinhas polpa e polpa com casca de goiaba.

Os teores de umidade, determinados para as duas farinhas, não apresentaram diferença significativa $(p>0,05)$ entre si. Os valores obtidos estão dentro dos limites estabelecidos pela Agência Nacional de Vigilância Sanitária (ANVISA), que estabelece o máximo de $15 \%(\mathrm{~m} / \mathrm{m})$ de umidade para farinhas (BRASIL, 2005). Com a umidade das farinhas inferior a $13,50 \mathrm{~g}(100 \mathrm{~g})^{-1}$, pode-se considerar que tais produtos possuem boa estabilidade física e química, desde que sejam estocados adequadamente em embalagens hermeticamente fechadas (FERTONANI, 2006).

$\mathrm{A}$ atividade de água média diferiu $(\mathrm{p}<0,05)$ entre as farinhas avaliadas. No entanto, considerando-se que a faixa de atividade de água para o crescimento microbiano em produtos desidratados é de 0,60 (SANJINEZ-ARGANDOÑA et al., 2005), as farinhas podem ser consideradas microbiologicamente estáveis, desde que armazenadas adequadamente.

O teor de cinzas da farinha da polpa foi significativamente inferior $(\mathrm{p}<0,05)$ ao encontrado para a farinha da polpa com casca. Segundo Gondim et al. (2005), as cascas das frutas

Tabela 2. Características físicas e químicas das farinhas da polpa e polpa com casca de goiaba.

\begin{tabular}{lrrr}
\hline \multicolumn{1}{c}{ Característica } & \multicolumn{1}{c}{ Polpa $^{1}$} & \multicolumn{1}{c}{$\begin{array}{c}\text { Polpa com } \\
\text { casca }^{1}\end{array}$} & CV \\
\hline Umidade (g.100 g & \\
Atividade de água & $12,55^{\mathrm{a}} \pm 0,44$ & $13,24^{\mathrm{a}} \pm 0,28$ & 0,04 \\
Cinzas (g.100 g-1) & $0,40^{\mathrm{b}} \pm 0,01$ & $0,45^{\mathrm{a}} \pm 0,00$ & 0,01 \\
Açúcares totais(g.100 g g-1) & $1,89^{\mathrm{b}} \pm 0,38$ & $2,69^{\mathrm{a}} \pm 0,24$ & 0,11 \\
Açúcares redutores (g.100 g $\left.{ }^{-1}\right)$ & $31,45^{\mathrm{a}} \pm 1,05$ & $33,12^{\mathrm{a}} \pm 1,72$ & 0,04 \\
pH & $9,83^{\mathrm{a}} \pm 0,15$ & $9,03^{\mathrm{b}} \pm 0,10$ & 0,02 \\
Acidez total (g.100g ác. cítrico $\left.{ }^{-1}\right)$ & $4,28^{\mathrm{a}} \pm 0,02$ & $4,29^{\mathrm{a}} \pm 0,01$ & 0,00 \\
Pectina (g pectato de cálcio.100g $\left.\mathrm{g}^{-1}\right)$ & $2,27^{\mathrm{a}} \pm 0,04$ & $2,12^{\mathrm{a}} \pm 0,05$ & 0,02 \\
\hline
\end{tabular}

CV: coeficiente de variação; $\mathrm{e}^{1}$ médias seguidas de letras sobrescritas iguais na linha não diferem entre si ao nível de 5\% de probabilidade pelo teste Tukey. 
apresentam quantidades de minerais maiores que as suas partes comestíveis. O teor de cinzas da farinha de casca de goiaba foi semelhante ao encontrado por Kliemann (2006) para farinha da casca do maracujá amarelo com flavedo (3,36 g.100 g-1). No estudo com farinha de banana verde, Fasolin et al. (2007) reportaram valores próximos aos encontrados $\left(2,62\right.$ g. $\left.100 \mathrm{~g}^{-1}\right)$. Entretanto, trabalhos realizados com farinha de trigo (GUTKOSKI; NODARI; JACOBSEN-NETO, 2003) e farinha de mandioca (CHISTÉ et al. 2007) apresentaram teores de cinzas de 0,50 g. $100 \mathrm{~g}^{-1}$ e de $0,54 \mathrm{~g} .100 \mathrm{~g}^{-1}$, respectivamente, cujos valores são inferiores aos obtidos para as farinhas a partir da goiaba. Esses estudos sugerem que a composição centesimal de vegetais difere de acordo com a classificação botânica do fruto, tipo de solo, condições edafoclimáticas, entre outros.

O conteúdo de açúcares redutores na farinha de polpa com casca foi menor que na de polpa, provavelmente pela composição química da casca constituída de polissacarídeos de cadeia longa, enquanto que os açúcares totais não diferiram $(\mathrm{p}>0,05)$ entre as farinhas estudadas devido à hidrólise dos polissacarídeos. Os valores obtidos para o conteúdo de açúcares foram semelhantes aos reportados por Fertonani (2006) para a farinha do bagaço de maçã $c v$ Joaquina $\left(33,44\right.$ g. $\left.100 \mathrm{~g}^{-1}\right)$ e por Canteri-Schemin (2003) para $c v$ Belgolden (32,54 g. $\left.100 \mathrm{~g}^{-1}\right)$. Na farinha de banana verde, foram encontrados apenas traços de açúcares totais e redutores (FASOLIN et al. 2007). Considerando-se que os açúcares totais representam sensorialmente a doçura da fruta e que no processo bioquímico do amadurecimento há conversão de amido em açúcares, é esperado que a maçã e a goiaba apresentem maior teor do que a banana verde.

Os valores de $\mathrm{pH}$ das farinhas analisadas $(4,28$ e 4,29) foram semelhantes aos da fruta fresca, obtida por diversos autores (FERTONANI, 2006; SANJINEZ-ARGANDOÑA et al., 2005), sendo considerados produtos ácidos ( $\mathrm{pH} 4,0-4,5)$, o que constitui um fator desfavorável ao crescimento de microrganismos patogênicos (JAY, 2005). As médias de acidez titulável não diferiram estatisticamente $(\mathrm{p}>0,05)$ entre si, o que era esperado em função dos valores de $\mathrm{pH}$ obtidos para essas amostras.

Em relação ao conteúdo de pectina, não foram encontrados na literatura outros trabalhos com farinha de goiaba. No entanto, Linhares et al. (2007), estudando polpas de goiaba Pedro Sato, relataram teor de pectina total de $0,88 \mathrm{~g} \cdot 100 \mathrm{~g}^{-1}$. Vila et al. (2007) obtiveram valores em torno de 0,66 g. $100 \mathrm{~g}^{-1}$ e Xisto et al. (2004) observaram valores de pectina $0,4 \mathrm{~g}(100 \mathrm{~g})^{-1}$ para a mesma cultivar.

\subsection{Rendimento da extração de pectina}

A Tabela 3 apresenta os rendimentos médios de pectina extraída das farinhas de polpa e de polpa com casca de goiaba.

Os rendimentos médios de pectina extraída a partir da farinha de polpa de goiaba $c v$ Pedro Sato variaram entre 7,83-13,66 g.100 g ${ }^{-1}$. Foram observados os maiores valores de rendimento de pectina nos experimentos $2,4,6,8,9,10$ e 11 (concentrações de ácido cítrico de 5 a $7 \mathrm{~g} .100 \mathrm{~g}^{-1}$ ). Os mesmos não diferiram $(\mathrm{p}>0,05)$ entre si, mas diferiram $(\mathrm{p}<0,05)$ dos demais. Os experimentos 3 e 5 também não diferiram $(p>0,05)$ entre si, o mesmo ocorrendo com os experimentos 1 e 7 , que obtiveram os menores rendimentos.

Na Figura 1, são mostrados os efeitos linear (L) e quadrático (Q) das variáveis: concentração de ácido cítrico e tempo e suas interações sobre o rendimento de extração de pectina da farinha de polpa de goiaba. Os efeitos com valores maiores que 2,01 $(\mathrm{P}=0,05)$, localizados à direita da linha tracejada, foram significativos. Assim, observa-se que as variáveis: ácido (L) e tempo (L) apresentam efeito positivo no rendimento da extração de pectina. Isto indica que o aumento em qualquer um destas variáveis, dentro das faixas estudadas, acarreta aumento no rendimento, enquanto que o efeito da variável tempo (Q) tem influência negativa; de forma inversa, um aumento desta variável causa diminuição no rendimento. Todavia, a influência da concentração do ácido foi duas vezes superior à influência

Tabela 3. Rendimento da extração de pectina a partir de farinhas da polpa e polpa com casca de goiaba baseado na concentração de ácido cítrico e tempo de extração segundo o planejamento experimental

\begin{tabular}{cccccc}
\hline Experimento & \multicolumn{2}{c}{ Variáveis } & & \multicolumn{2}{c}{ Respostas } \\
\cline { 2 - 3 } \cline { 5 - 6 } & $\begin{array}{c}\text { Ácido } \\
\left(\mathrm{g} .100 \mathrm{~g}^{-1}\right)\end{array}$ & $\begin{array}{c}\text { Tempo } \\
(\text { minutos })\end{array}$ & & $\begin{array}{c}\text { Polpa }^{1} \\
\left(\mathrm{~g} .100 \mathrm{~g}^{-1}\right)\end{array}$ & $\begin{array}{c}\text { Polpa com } \\
\text { casca }^{1} \\
\left(\mathrm{~g} .100 \mathrm{~g}^{-1}\right)\end{array}$ \\
\hline 1 & 3,5 & 35 & $7,83^{\mathrm{c}}$ & $7,31^{\mathrm{e}}$ \\
2 & 6,5 & 35 & & $13,64^{\mathrm{a}}$ & $10,57^{\mathrm{b}}$ \\
3 & 3,5 & 85 & & $9,38^{\mathrm{b}}$ & $8,87^{\mathrm{c}, \mathrm{d}, \mathrm{e}}$ \\
4 & 6,5 & 85 & & $12,90^{\mathrm{a}}$ & $10,64^{\mathrm{b}, \mathrm{d}, \mathrm{d}}$ \\
5 & 3 & 60 & & $9,56^{\mathrm{b}}$ & $8,49^{\mathrm{d}, \mathrm{e}}$ \\
6 & 7 & 60 & & $13,66^{\mathrm{a}}$ & $13,24^{\mathrm{a}}$ \\
7 & 5 & 25 & & $7,91^{\mathrm{c}}$ & $5,91^{\mathrm{f}}$ \\
8 & 5 & 95 & & $12,77^{\mathrm{a}}$ & $12,85^{\mathrm{a}, \mathrm{b}}$ \\
9 & 5 & 60 & & $12,52^{\mathrm{a}}$ & $11,41^{\mathrm{a}, \mathrm{b}}$ \\
10 & 5 & 60 & & $12,75^{\mathrm{a}}$ & $11,81^{\mathrm{a}, \mathrm{b}}$ \\
11 & 5 & 60 & & $12,44^{\mathrm{a}}$ & $11,36^{\mathrm{a}, \mathrm{b}, \mathrm{c}}$ \\
\hline
\end{tabular}

${ }^{\star}$ Letras iguais entre colunas não diferem estatisticamente entre si $(\mathrm{p}>0,05) ; \mathrm{e}^{1}$ os valores representam média de duas observações.

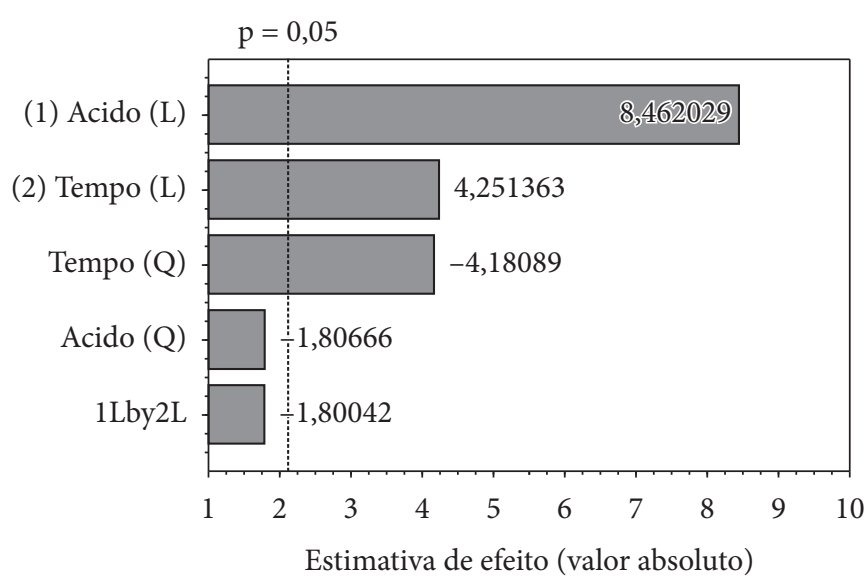

Figura 1. Efeito das variáveis "concentração de ácido cítrico" e "tempo" e suas interações sobre o rendimento de extração de pectina da farinha de polpa de goiaba $c v$ Pedro Sato. (L) corresponde a efeito linear e (Q) a efeito quadrático. 
do efeito do tempo de extração. Por sua vez, os efeitos linear e quadrático do tempo de extração foram próximos em valor absoluto. Segundo Kalapathy e Proctor (2001), tempos de extração longos favorecem a degradação da molécula de pectina, principalmente quando associada à alta concentração de ácido. Canteri-Schemin (2003) verificou comportamento semelhante das variáveis independentes (concentração de ácido cítrico e tempo de extração) para a extração de pectina de bagaço de maçã com ácido cítrico, na qual os efeitos lineares foram positivos e os quadráticos negativos. Calliari (2004) obteve, na extração de pectina de bagaço de laranja com ácido cítrico, efeito linear positivo para o ácido e efeito quadrático positivo para a temperatura de extração, já na extração com ácido acético, somente a temperatura apresentou efeito significativo.

As concentrações de ácido cítrico entre 5-7 g $(100 \mathrm{~g})^{-1}$, experimentos $2,4,6,8,9,10$ e 11 , promoveram maiores rendimentos de extração de pectina a partir da polpa, estatisticamente significativos entre si, variando apenas o tempo de extração. Entretanto, conforme discutido anteriormente, tempos relativamente longos de extração podem degradar a pectina diminuindo a quantidade a ser precipitada com álcool, devido à formação de um gel fraco, o que ocasiona redução no rendimento final da pectina (PAGAN et al., 2001), assim como concentrações mais elevadas de ácidos podem degradar a pectina. No caso do ácido cítrico, segundo Fertonani et al. (2006), a pectina extraída com altas concentrações deste ácido, pode conter também outros compostos, ou ainda, pode ocorrer ligação do ácido cítrico à estrutura péctica. CanteriSchemin et al. (2005), na extração de pectina a partir de bagaço de maçã, utilizando ácidos tartárico, málico, cítrico, fosfórico, sulfúrico, clorídrico e nítrico, obtiveram melhores rendimentos com ácido cítrico nas concentrações de 0,05 a $9,95 \mathrm{~g}(100 \mathrm{~mL})^{-1}$ a $97^{\circ} \mathrm{C}$, em um intervalo de tempo variando de 10 a 210 minutos. Nos ensaios realizados, a pectina extraída com 5 g. $100 \mathrm{~g}^{-1} \mathrm{de}$ ácido cítrico durante 60 minutos apresentou melhor formação de gel, observado visualmente pela sua firmeza.

Os rendimentos observados para a farinha da polpa com casca de goiaba (Tabela 3) oscilaram entre 5,91-12,85 g (100 g $)^{-1}$. Os experimentos 6, 8, 9, 10 e 11 não diferiram ( $p>0,05)$ entre si. Nestes experimentos, foram observados os maiores valores de rendimento de pectina $\left(11,36\right.$ a 13,24 g. $\left.100 \mathrm{~g}^{-1}\right)$. Os rendimentos médios dos experimentos $2,4,8,9,10$ e 11 também não diferiram $(\mathrm{p}>0,05)$ entre si, o mesmo ocorrendo entre os experimentos 3 , 4, e $11 ; 3$ e 5 ; e 1 e 5 . O experimento 7 obteve o menor rendimento e diferiu $(\mathrm{p}<0,05)$ dos demais.

A análise de variância dos resultados mostrou que os efeitos lineares para as variáveis concentração de ácido cítrico, tempo de extração e o efeito quadrático da variável tempo, foram significativos $(\mathrm{p}<0,05)$, porém o efeito $(\mathrm{Q})$ da variável concentração de ácido e a interação entre as duas variáveis (ácido e tempo) não foram significativos ( $\mathrm{p}>0,05)$. O diagrama de Pareto (Figura 2) mostra a influência dos efeitos lineares positivos da concentração de ácido cítrico e do tempo sobre o rendimento de pectina, seguido pelo efeito quadrático negativo do tempo de extração. Percebe-se que a influência da concentração do ácido foi semelhante à influência do efeito do tempo de extração. Fertonani (2006) verificou comportamento semelhante das variáveis

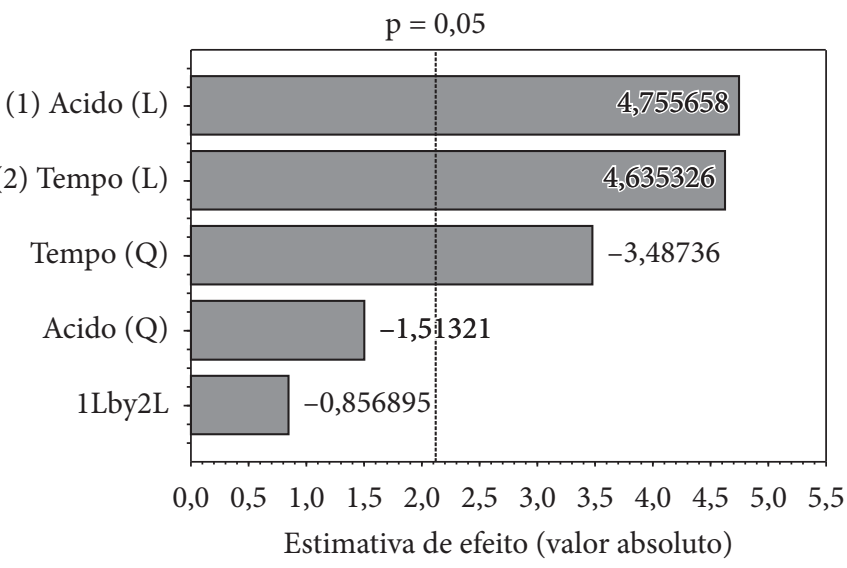

Figura 2. Efeito das variáveis "concentração de ácido cítrico" e "tempo" e suas interações no rendimento de extração de pectina a partir da farinha de polpa com casca de goiaba $c v$ Pedro Sato. (L) corresponde a efeito linear e $(\mathrm{Q})$ a efeito quadrático.

independentes (concentração de ácido e tempo de extração) para extração de pectina de bagaço de maçã com ácido nítrico, na qual os efeitos lineares foram positivos e os quadráticos negativos. Kliemann (2006), no estudo da extração de pectina da casca do maracujá amarelo com diversos ácidos, observou, na extração com ácido cítrico, efeitos lineares, negativo para o pH da solução e positivo para a temperatura de extração, e efeitos quadráticos negativos para ambas as variáveis. Na extração com ácido clorídrico, a temperatura e o tempo de extração apresentaram efeitos lineares positivos e efeitos quadráticos negativos; com o ácido nítrico a temperatura e o tempo apresentaram somente efeitos lineares positivos.

Os rendimentos para a farinha da polpa com casca foram maiores nas concentrações de 5, 6,5 e 7 g. $100 \mathrm{~g}^{-1}$ de ácido cítrico, com exceção para o experimento $\mathrm{n}^{\circ} 7$ (Tabela 3). Em concentrações de 5 g. $100 \mathrm{~g}^{-1}$ de ácido, o tempo de extração parece influenciar positivamente, porém, dependendo da temperatura de extração, tempos maiores poderão acarretar a degradação da pectina (PAGAN et al., 2001). Verificou-se, nessa concentração e no tempo de 60 minutos, melhor formação do gel, semelhante ao observado na extração com a farinha da polpa.

Poucos trabalhos foram encontrados na literatura em relação ao uso da casca de vegetais. Kliemann (2006), em amostras de casca de maracujá amarelo com e sem flavedo, obteve melhor rendimento de pectina nas condições de extração por 10 minutos a $90^{\circ} \mathrm{C}$ e pH de 1,2 ajustado com ácido cítrico. Kalapathy e Proctor (2001) que estudaram a obtenção de pectina a partir da casca de soja, avaliaram o rendimento de extração utilizando ácido clorídrico nas concentrações de 0,06 a 0,18 g. $100 \mathrm{~g}^{-1}(0,05$ e 0,3 N) e verificaram que os maiores rendimentos (17 e 19\%) foram obtidos nas concentrações 0,06 e 0,12 g. $100 \mathrm{~g}^{-1}$, não havendo diferença significativa entre ambas as concentrações.

\subsection{Características titulométricas das pectinas}

As características de qualidade das pectinas são apresentadas na Tabela 4. 
Tabela 4. Características titulométricas da pectina comercial e da pectina extraída a partir das farinhas de polpa e de polpa com casca de goiaba na condição de extração de $5 \mathrm{~g} .100 \mathrm{~g}^{-1}$ ácido cítrico a $97^{\circ} \mathrm{C}$ por 60 minutos.

\begin{tabular}{|c|c|c|c|c|c|}
\hline \multirow{2}{*}{$\begin{array}{l}\text { Pectinas das farinhas de } \\
\text { goiaba e comercial }\end{array}$} & \multicolumn{5}{|c|}{ Características da pectina } \\
\hline & $\begin{array}{c}\text { Ácidos galacturônicos } \\
\text { (AUA) } \\
\left(\mathrm{g} .100 \mathrm{~g}^{-1}\right)\end{array}$ & $\begin{array}{l}\text { Metoxilas } \\
(\mathrm{MeO}) \\
\left(\mathrm{g} .100 \mathrm{~g}^{-1}\right)\end{array}$ & $\begin{array}{l}\text { Fração ácida } \\
\left(\mathrm{g} .100 \mathrm{~g}^{-1}\right)\end{array}$ & $\begin{array}{l}\text { Açúcares Neutros } \\
\left(\mathrm{g} .100 \mathrm{~g}^{-1}\right)\end{array}$ & $\begin{array}{c}\text { Grau de esterificação } \\
(\mathrm{DE}) \\
\left(\mathrm{g} .100 \mathrm{~g}^{-1}\right)\end{array}$ \\
\hline Farinha de polpa & $64,88^{c} \pm 0,11$ & $4,45^{\mathrm{b}} \pm 0,40$ & $69,33^{c} \pm 0,29$ & $30,67^{a} \pm 0,29$ & $38,94^{\mathrm{b}} \pm 1,50$ \\
\hline Farinha de polpa com casca & $68,84^{\mathrm{b}} \pm 0,77$ & $4,95^{\mathrm{b}} \pm 0,16$ & $73,81^{\mathrm{b}} \pm 0,73$ & $26,19^{b} \pm 0,73$ & $40,99^{\mathrm{b}} \pm 1,30$ \\
\hline
\end{tabular}

Médias seguidas de letras sobrescritas iguais na coluna não diferem entre si ao nível de $5 \%$ de probabilidade pelo teste Tukey.

As pectinas obtidas a partir das farinhas de polpa e de polpa com casca de goiaba apresentaram características semelhantes em relação ao teor de metoxilas, porém, os valores obtidos foram menores aos encontrados para a pectina comercial, diferindo significativamente $(p<0,05)$. Entretanto, os valores obtidos foram similares aos encontrados por Fertonani et al. (2006) para pectina de bagaço de maçã extraída com ácido nítrico na concentração de $100 \mathrm{mMol}(\mathrm{L})^{-1}$ a $97^{\circ} \mathrm{C}$ por 10 minutos.

Em relação aos ácidos galacturônicos, apesar de apresentarem diferença significativa $(\mathrm{p}<0,05)$, os valores obtidos estão próximos à porcentagem mínima de ácido galacturônico para pectinas comerciais $(65 \%)$ estabelecida pela FAO (FOOD AND AGRICULTURE ORGANIZATION OF THE UNITED NATIONS, 1994). Calliari (2004), em pectinas extraídas de bagaço de laranja com $3,5 \%$ de ácido cítrico a $75{ }^{\circ} \mathrm{C}$, reportou $64,10 \%$ de AUA, porcentagem próxima à obtida na farinha de polpa de goiaba.

As pectinas obtidas a partir das farinhas estudadas, neste trabalho, apresentaram grau de esterificação inferior a $50 \%$, sendo caracterizadas como pectinas de baixo teor de esterificação. Calliari (2004) obteve valor semelhante (37,50\%) para pectina extraída com ácido cítrico a partir de bagaço de laranja nas condições de $4 \%$ de bagaço, 3,5\% de ácido cítrico a $75{ }^{\circ} \mathrm{C}$. Kliemann (2006) também extraiu pectina de baixa esterificação $(45,94 \%)$ utilizando ácido cítrico em pH 1,2 a $90{ }^{\circ} \mathrm{C}$ por 10 minutos na extração e cascas de maracujá como matéria-prima. Marcon et al. (2005) extraíram pectina de baixa esterificação (14,3 a 29,4\%) de bagaço de maçã com ácido cítrico a 5\%, tempos de extração entre 30-80 minutos e temperaturas entre $50-100^{\circ} \mathrm{C}$.

As pectinas de baixo poder de esterificação possibilitam a formação de géis estáveis na ausência de açúcares e na presença de alguns íons metálicos. Em comparação com as pectinas de alto poder de esterificação, são menos sensíveis a alterações de $\mathrm{pH}$, formando géis na faixa de $\mathrm{pH}$ 2,6-6,0, podendo também ser empregadas como fibra dietética solúvel, espessante e estabilizante de emulsões em alimentos (SHARMA; LIPTAY; LE MAGUER, 1998; YAPO et al. 2007).

\section{Conclusões}

O processo de extração de pectina com ácido cítrico e precipitação alcoólica em sistema de ebulição apresentou rendimentos acima de $11 \%$ para a farinha de polpa e de polpa com casca de goiaba. As melhores condições de extração foram: concentração de ácido de 5 g. $100 \mathrm{~g}^{-1}$ e tempo de extração de 60 minutos.

As pectinas obtidas nas melhores condições de extração apresentaram grau de esterificação inferior a $50 \%$, sendo consideradas de baixa esterificação. No entanto, o teor de ácido galacturônico foi próximo à pectina comercial.

As pectinas extraídas podem ser empregadas na geleificação de alimentos com baixo teor de açúcar, como fibra dietética solúvel, espessante e estabilizante em alimentos.

\section{Referências bibliográficas}

BRASIL. Resolução n. 263, de 22 de setembro de 2005. Aprova regulamento técnico para produtos de cereais, amidos, farinhas e farelos. Diário Oficial [da] República Federativa do Brasil, Poder Executivo, Brasília, DF, 22 set. 2005. Disponível em: <http://www. anvisa.gov.br>. Acesso em: 10 jul. 2007.

CALLIARI, C. M. Extração térmica, química e enzimática de pectina de bagaço de laranja. Londrina, 2004. 96 p. Dissertação (Mestrado em Ciência dos Alimentos) - Universidade Estadual de Londrina - UEL.

CANTERI-SCHEMIN, M. H. et al. Extraction of pectin from apple pomace. Brazilian Archives of Biology and Technology, v. 48, n. 2, p. 259-266, 2005.

CANTERI-SCHEMIN, M. H. Obtenção de pectina alimentícia a partir de bagaço de maçã. Curitiba, 2003. 83 p. Dissertação (Mestrado em Tecnologia de Alimentos) - Universidade Federal do Paraná - UFPR.

CERQUEIRA, T. S. Recobrimentos comestíveis em goiabas cv. “Kumagai”. Piracicaba, 2007. 70 p. Dissertação (Mestrado em Ciências de Alimentos) - Universidade de São Paulo - USP.

CHISTÉ, R. C. et al. Estudo das propriedades físico-químicas e microbiológicas no processamento da farinha de mandioca do grupo d'água. Ciência e Tecnologia de Alimentos, v. 27, n. 2, p. 265-269, 2007.

FASOLIN, L. H. et al. Biscoitos produzidos com farinha de banana: avaliações química, física e sensorial. Ciência e Tecnologia de Alimentos, v. 27, n. 3, p. 524-529, 2007.

FERTONANI, H. C. R. Estabelecimento de um modelo de extração ácida de pectina de bagaço de maçã. Ponta Grossa, 2006. 82 p. Dissertação (Mestrado em Ciência e Tecnologia de Alimentos) Universidade Estadual de Ponta Grossa - UGPG.

FERTONANI, H. C. R. et al. Influência da concentração de ácidos no processo de extração e na qualidade de pectina de bagaço de maçã. Semina: Ciências Agrárias, v. 27, n. 4, p. 599-612, 2006. 
FIETZ, V. R.; SALGADO, J. M. Efeito da pectina e da celulose nos níveis séricos de colesterol e triglicerídeos em ratos hisperlipidêmicos. Ciência e Tecnologia de Alimentos, v. 19, n. 3, p. 318-321, 1999.

FOOD AND AGRICULTURE ORGANIZATION OF THE UNITED NATIONS - FAO. Health (emulsifiers, stabilisers, thickeners and gelling agents in food) regulations 1994. Roma, 2008. Disponível em: <http://www.fao.org.com>. Acesso em: 08 abr. 2008.

GNANASAMBANDAM, G.; PROCTOR, A. Preparation of soy hull pectin. Food Chemistry, v. 65, n. 4, p. 461-467, 1999.

GONDIM, J. A. M. et al. Composição centesimal e de minerais em cascas de frutas. Ciência e Tecnologia de Alimentos, v. 25, n. 4, p. 825-827, 2005.

GUTKOSKI, L. C.; NODARI, M. L.; JACOBSEN-NETO, R. Avaliação de farinhas de trigos cultivados no Rio Grande do Sul na produção de biscoitos. Ciência e Tecnologia de Alimentos, v. 23, supl., p. 91-97, 2003.

INSTITUTO ADOLFO LUTZ - IAL. Normas analíticas do Instituto Adolfo Lutz. São Paulo, 2005. 533 p.

JAY, J. M. Microbiologia de Alimentos. São Paulo: Artmed, 2005. $712 \mathrm{p}$.

KALAPATHY, U.; PROCTOR, A. Effect of acid extraction and alcohol precipitation conditions on the yeld and purity of soy hull pectin. Food Chemistry, v. 73, n. 4, p. 393-396, 2001.

KLIEMANN, E. Extração e caracterização da pectina da casca do maracujá amarelo (Passiflora edulis flavicarpa). Florianópolis, 2006. 75 p. Dissertação (Mestrado em Ciência dos Alimentos) Universidade Federal de Santa Catarina - UFSC.

LINHARES. L. A. et al. Transformações químicas, físicas e enzimáticas de goiabas "PEDRO SATO" tratadas na pós-colheita com cloreto de cálcio e 1-metilciclopropeno e armazenadas sob refrigeração. Ciência e Agrotecnologia, v. 31, n. 3, p. 829-841, 2007.

MARCON, M. V. et al. Pectins from apple pomace. Polímeros: Ciência e Tecnologia, v. 15, n. 2, p. 127-129, 2005.

MAY, C. D. Industrial pectins: sources, production and applications. Carbohydrate Polymers, v. 12, n. 15, p. 79-99, 1990.

ORDOÑEZ-PEREDA, J. A. Carboidratos. In: Tecnologia dos alimentos: componentes dos alimentos e processos. São Paulo: Artmed, 2005. p. 63-79. (v. 1, cap. 4)
PAGÁN, J. et al. Extraction and chacarterization of pectin from stored peach pomace. Food Research International, v. 34, n. 7, p. 605-612, 2001.

PIEDADE, J.; CANNIATTI-BRAZACA, S. G. Comparação entre o efeito do resíduo do abacaxizeiro (caules e folhas) e da pectina cítrica de alta metoxilação no nível de colesterol sanguíneo em ratos. Ciência e Tecnologia de Alimentos, v. 23, n. 2, p. 149-156, 2003.

RANGANNA, S. Manual of analysis of fruit and vegetable products. New Delhi: Tata McGraw Hill Publishing Company Ltd, 1977. $634 \mathrm{p}$.

SANJINEZ-ARGANDONAA, E. J. et al. Evaluation of total carotenoids and ascorbic acid in osmotic pretreated guavas during convective drying. Italian Journal of Food Science, v. 17, n. 3, p. 305-314, 2005.

SAS INSTITUTE. The SAS system for Windows 3.95-Release 6.08. Cary, 1992.

SHARMA, S. K.; LIPTAY, A.; LE MARGUER, M. Molecular characterization, physico-chemical and functional properties tomato fruit pectin. Food Research International, v. 30, n. 7, p. 543-547, 1998.

TERPSTRA, A. H. M. et al. Dietary pectin with high viscosity lowers plasma and liver cholesterol concentration and plasma cholesteryl ester protein activity in hamsters. The Journal of Nutrition, v. 128, n. 11, p. 1944-1949, 1998.

THAKUR, B. R.; SINGH, R. K.; HANDA, A. K. Chemistry and uses of pectin: a review. Critical Reviews in Food Science and Nutrition, v. 37, n. 1, p. 47-73, 1997.

VILA, M. T. R. et al. Caracterização química e bioquímica de goiabas armazenadas sob refrigeração e atmosfera modificada. Ciência e Agrotecnologia, v. 31, n. 5, p. 1435-1442, 2007.

WILlATS, W. G. T.; KNOX, J. P.; MIKKELSEN, J. D. Pectin: new insights into and old polymers are starting to gel. Trends in Food Science \& Technology, v. 17, n. 3, p. 97-104, 2006.

XISTO, A. L. R. P. et al. Textura de goiabas "Pedro Sato" submetidas à aplicação de cloreto de cálcio. Ciência e Agrotecnologia, v. 28, n. 1, p. 113-118, 2004.

YAPO, B. M. et al. Effect of extraction conditions on the yield, purity and surface properties of sugar beet pulp pectin extracts. Food Chemistry, v. 100, n. 4, p. 1356-1364, 2007. 